\title{
What makes Haloxylon persicum grow on sand dunes while $H$. ammodendron grows on interdune lowlands: a proof from reciprocal transplant experiments
}

\author{
GuiQing XU, DanDan YU, JiangBo XIE, LiSong TANG, Yan LI* \\ State Key Laboratory of Desert and Oasis Ecology, Xinjiang Institute of Ecology and Geography, Chinese Academy of Sciences, Urumqi \\ 830011, China
}

\begin{abstract}
Determining the mechanisms underlying the spatial distribution of plant species is one of the central themes in biogeography and ecology. However, we are still far from gaining a full understanding of the autecological processes needed to unravel species distribution patterns. In the current study, by comparing seedling recruitment, seedling morphological performance and biomass allocation of two Haloxylon species, we try to identify the causes of the dune/interdune distribution pattern of these two species. Our results show the soil on the dune had less nutrients but was less saline than that of the interdune; with prolonged summer drought, soil water availability was lower on the dune than on the interdune. Both species had higher densities of seedlings at every stage of recruitment in their native habitat than the adjacent habitat. The contrasting different adaptation to nutrients, salinity and soil water conditions in the seedling recruitment stage strongly determined the distribution patterns of the two species on the dune/interdune. Haloxylon persicum on the dunes had lower total dry biomass, shoot and root dry biomass, but allocated a higher percentage of its biomass to roots and possessed a higher specific root length and specific root area by phenotypic traits specialization than that of Haloxylon ammodendron on the interdune. All of these allowed $H$. persicum to be more adapted to water stress and nutrient shortage. The differences in morphology and allocation facilitated the ability of these two species to persist in their own environments.
\end{abstract}

Keywords: Haloxylon; seedling recruitment; root distribution; biomass allocation; species distribution

\begin{abstract}
Citation: GuiQing XU, DanDan YU, JiangBo XIE, LiSong TANG, Yan LI. 2014. What makes Haloxylon persicum grow on sand dunes while $H$. ammodendron grows on interdune lowlands: a proof from reciprocal transplant experiments. Journal of Arid Land, 6(5): 581-591. doi: 10.1007/s40333-014-0029-1
\end{abstract}

Spatial patterns of species diversity and species distribution are central to ecology and have fascinated naturalists, ecologists and biogeographers for centuries (Zimmermann et al., 2009; Eiserhardt et al., 2011). The factors influencing species distribution have become a major concern and attention has been focused on the roles played by climate (Honnay et al., 2002; Svenning and Skov, 2007), topography and habitat heterogeneity (John et al., 2007), dispersal (Svenning et al., 2008) and biotic interactions (Richards et al., 1997; Araújo and Luoto, 2007). However, determinants of species distributions vary on spatial and tem- poral scales. For instance, climate appears to be important at the landscape level and above (Davis and Shaw, 2001; Walther et al., 2007). Soil or topography dominates at landscape and local scales, hydrology at local scales, and dispersal functions at all scales (Angert and Schemske, 2005). Therefore, understanding the mechanisms underlying the size, shape and dynamics of the geographic distributions of various species remains a key challenge (Pennisi, 2005; Gaston, 2009). Specifically, as the causes of species distributions do not function independently (McDowall, 2004) and are scale dependent (Levin, 1992), the importance

*Corresponding author: Yan LI (E-mail: liyan@ms.xjb.ac.cn) 
of different mechanisms varies with scales (Hu et al.,2012; Schei et al., 2012).

At local $(<1,000 \mathrm{~m})$ to regional scales $(100 \mathrm{~km})$, Tuomisto and Poulsen (1996), Richards et al. (1997), and John et al. (2007) reported plant species' distributions are strongly associated with edaphic conditions including soil chemistry and nutrient availability. The influence of soil texture on hydrological conditions may affect plant species distributions and diversity (Rietkerk et al., 2002; Palm et al., 2007). Also, topography may affect plant distributions indirectly by modulating other environmental factors such as soil conditions, hydrology, wind exposure, as well as temperature and fog frequency (Svenning, 2001; Swenning et al., 2009). Although the influence of environmental conditions on plant distribution patterns have been well documented in the local scales, the related process and mechanisms causing these patterns are still poorly known, especially for tree species (Engelbrecht et al., 2007). Far less attention has been paid to the dominant processes and mechanisms mediating tree species distribution patterns during various life stages.

Among the main processes and mechanisms of population ecology, the regeneration stage is often the most critical stage during the life history of plants in determining adult plant distribution (Davis, 1991; Pratt et al., 2008), especially as it relates to adaptation to local edaphic and microclimatic conditions during germination and seedling establishment (Mustart and Cowling, 1993; Daws et al., 2002; Masaki et al., 2007). A reciprocal transplant approach had been considered to be an effective method to ascertain the importance of edaphic factors on seedling establishment and species distribution (Wang et al., 1997). By monitoring seedlings emergence, establishment, and mortality of species on their own and adjacent soils in natural habitats, the edaphic factors that determine the seedling distribution can be determined (Mustart and Cowling, 1993; Richards et al., 1997).

Furthermore, phenotypic plasticity, morphological characteristics and biomass allocation have long been proposed to be the key mechanisms used by plant species to adaptively maintain distributions by enhancing physiological and demographic components of fitness (Poot and Lambers, 2003; Pichancourt and van Klinken, 2012) and thus can also affect species distri- bution (Pohlman et al., 2005; Pineda-GarcíA et al., 2011; Pichancourt and van Klinken, 2012). However, the role of morphologic traits and biomass allocation in influencing species geographic distributions has not yet been clarified in the field (Poot and Lambers 2003; Ellers and Stuefer, 2010).

Haloxylon ammodendron (C. A. Mey.) Bunge and H. persicum Bunge ex Boiss. et Buhse (Chenopodiaceae) are two xerophytic desert trees (Song et al., 2005). H. ammodendron occurs naturally in various habitats, including gravel desert, clay desert, fixed and semi-fixed sand, and saline land in Asian and African deserts (Tobe et al., 2000). H. persicum occurs naturally in non-saline sandy deserts in Central Asia, the Middle East, Afghanistan, northwestern China and Near Eastern deserts (Song et al., 2005; Al-Khalifah and Shanavaskhan, 2007). At the southern fringe of the Gurbantonggut Desert, the above two Haloxylon species are the major dominant species for their respective plant communities. H. ammodendron occupies interdunes and the flat slopes of dunes and $H$. persicum occurs mainly on the top of dunes, with both species rarely growing together. The contrasting distribution patterns of the two Haloxylon species have intrigued scientists in plant geography for many years. However, we are still far from fully understanding what controls this distribution pattern.

Sandy desert, characterized by the alternative distribution of sand dunes and interdune lowlands, usually shows a varying pattern of vegetation composition and contrasting plant community distribution on the dune and interdune habitats (Pemadasa et al., 1974; Avis and Lubke, 1996; Phillips et al., 2001; Liu et al., 2007). Desert dunes and interdune lowlands had been proven to provide habitat heterogeneity and to profoundly influence the spatial and temporal distribution of water and nutrients across the landscape (Rosenthal et al., 2005; Grigg et al., 2008; Zuo et al., 2009). Currently, topographic, edaphic and natural disturbance characteristics, such as the underground flow of saline water as well as sand movement or sand burial, influence species composition and distribution of dune ecosystems in deserts (Barnes and Harrison, 1982; Moreno-Casasola, 1988; Olff et al., 1993; Maun and Perumal, 1999). However, most of the research focused on coastal and lacustrine sand dune systems, making the results of such research barely applicable 
to sand dune systems in the continental interior such as the Gurbantonggut Desert in Central Asia. Previous studies in this typical temperate desert showed soil mechanical composition significantly affects the vegetation distribution. H. ammodendron benefits from coarse textured soil along environmental gradients (Xu et al., 2006). For H. ammodendron growing on soils with contrasting textures, phenotypic plasticity in root properties may have evolved to help plants enhance resource capture ( $\mathrm{Xu}$ and $\mathrm{Li}, 2008)$. Also, a study on the effects of sodium chloride $(\mathrm{NaCl})$ on germination and growth of $H$. ammodendron and $H$. persicum seedlings in the laboratory indicated $H$. ammodendron had higher tolerance to salinity than $H$. persicum (Tobe et al., 2000; Song et al., 2006). Salinity tolerance during seed germination and the seedling stage may determine the geographical distribution of both species (Tobe et al., 2000; Song et al., 2005). However, such conclusions were mostly drawn from laboratorial experiments and whether they are applicable in natural field conditions remained unknown.

In the current study, we adopted a comparative approach to germination and seedling recruitment by reciprocal transplanting in the field; morphological traits and biomass allocation of the two species were studied in seedlings. The working hypotheses were: (1) differences in regeneration (seed germination and/or seedling establishment of the two species) in a dune/interdune system determine the typical dune/interdune distribution of the adult trees; and (2) to adapt to different habitats, both species develop habitat specialization basing on their morphology and resource allocation patterns.

\section{Materials and methods}

\subsection{Habitat and species}

The field experiments were conducted during two growing seasons, during May to October 2009 and 2010, in their native habitats at the southern fringe of the Gurbantonggut Desert in the vicinity of the Fukang National Field Scientific Observation and Research Station for Desert Ecosystems $\left(44^{\circ} 17^{\prime} \mathrm{N}\right.$, $87^{\circ} 56^{\prime} \mathrm{E}$; $475 \mathrm{~m}$ asl). Typically, this region has a temperate, continental, arid climate, with dry, hot summers and cold winters. Annual precipitation is between 70 and $180 \mathrm{~mm}$ and annual pan evaporation is 10 times greater than annual precipitation. A site was selected for the experimental area far from human influence and in- cluding above two Haloxylon species with typical sand dunes-interdune lowlands distribution. Basing on a field survey from 5 sites, the mean density of adult trees was 120 plants $/ \mathrm{hm}^{2}$ for $H$. persicum and 700 plants $/ \mathrm{hm}^{2}$ for H. ammodendron in their respective habitats.

\subsection{Background data: soil physical and chemical properties}

Soil particle sizes were measured with a Malvern Laser Analyzer in the laboratory on soil samples of respective habitats from the experiment site. Bulk densities and degree of porosity were determined by conventional methods using a ring sampler. Stable infiltration rates were measured by a double-ring infiltrometer. The locations for sampling and measurements were randomly selection and carried out on top soil in each habitat with five replicates.

In each habitat, about $2 \mathrm{~kg}$ of dry soil was collected from 0 to $10 \mathrm{~cm}$ according to the germination depth and placed inside a paper-lined calico bag. The mixed soil samples were air-dried in a ventilated room and hand-sieved through $0.25-\mathrm{mm}$ mesh to remove roots and other organic debris. After the pretreatment, the mixed soil samples in each habitat were subsampled each with five replicates for the following analyses. Soil $\mathrm{pH}$ and electrical conductivity (EC) were measured in a soil-water suspension (1:5 soil:water ratio; $\mathrm{Li}$ et al., 2011). Soil organic carbon (SOC) was measured by the $\mathrm{K}_{2} \mathrm{Cr}_{2} \mathrm{O}_{7}-\mathrm{H}_{2} \mathrm{SO}_{4}$ oxidation method of Walkley-Black (Nelson and Sommers, 1982). Total soil N (TN) was measured by the Kjeldahl procedure (UDK140 Automatic Steam Distilling Unit, Automatic Titroline 96, Italy). Total soil P (TP) and K (TK) were measured with the $\mathrm{Mo}-\mathrm{Sb}$ antispectrophotography method using a spectrophotometer (UV-2401PC, Japan); concentrations of $\mathrm{PO}_{4}{ }^{3-}, \mathrm{NO}_{3}^{-}, \mathrm{NH}_{4}^{+}, \mathrm{K}^{+}, \mathrm{Na}^{+}$, $\mathrm{Ca}^{2+}, \mathrm{Mg}^{2+}, \mathrm{Cl}^{-}$and $\mathrm{SO}_{4}{ }^{2-}$ were determined using a capillary electrophoresis system, while $\mathrm{CO}_{3}{ }^{2-}$ and $\mathrm{HCO}_{3}^{-}$were determined by titration with $0.1 \mathrm{~mol} / \mathrm{L}$ $\mathrm{HCl}$ until the sample $\mathrm{pH}$ reached 4.3 (Patnaik, 1997).

The soil water content was measured within the profiles to $2-\mathrm{m}$ at $0.1-\mathrm{m}$ intervals, in the two habitats over the peak growing season from June to September 2010. Soil samples were extracted by an auger with three replicates at each depth every 5 days from three different randomly selected locations in each habitat. The samples were then stored in aluminum boxes and dried at $105^{\circ} \mathrm{C}$ to constant weight. To monitor the soil 
water content variation in the soil profile induced by the snow-melt in early spring, we measured the soil water content at $0.1-\mathrm{m}$ intervals from soil surface to the depth of $3 \mathrm{~m}$. The measurement was started on 28 March when the snow melting started and continued until the upper dry layer appeared on 25 April 2010, with three replicates at each depth.

Pressure membrane tests were conducted on the soil in the two habitats to determine the equilibrium water content retained in a soil subjected to pressures of $-0.1,-0.2$, $-0.5,-1.0,-1.2$ and $-1.5 \mathrm{MPa}$ in each plot. The data was used to obtain soil water release curves by fitting of the van Genuchten model (van Genuchten, 1980). We then used the curve fitted for each plot to calculate the soil matrix water potential basing on soil water content.

\subsection{Experiment 1: reciprocal seed transplants in the field}

We collected seeds near the study area in late October 2009, the year before conducting our seed planting experiment. We planted seeds at a depth of $5 \mathrm{~mm}$ in reciprocal transplants on 23 March 2010 before snow melt. At the sand dune and interdune lowland, 20 plots were seeded for each species with 10 plots on the dune and 10 plots on the interdune lowland randomly selected. The horizontal distance between the plots grouping on the dune/interdune was about $50 \mathrm{~m}$, totally there were 40 plots and each plot area was $1 \mathrm{~m} \times 1$ $\mathrm{m}$. In each plot, we planted 400 seeds in rows with the seeds $5 \mathrm{~cm}$ apart. We recorded the number of emerging seeds at 3-day intervals and checked survival at about 1 week intervals until the middle of September.

\subsection{Experiment 2: investigation of specific adap- tation in biomass allocation and morphology to their native habitats}

Five 1-year-old seedlings of each species from their natural habitat plots were chosen for excavation from their respective home plots on 20 September 2010 following the details provided by $\mathrm{Xu}$ and $\mathrm{Li}$ (2006) as described below. Tree height, basal stem diameter and canopy width were measured prior to excavation. A 1-m diameter ring ditch for the 1-year seedlings was dug around each target plant to uproot it. The huge cylinder of soil containing the rhizosphere was thus isolated, then rinsed off followed by the soil being removed by hand to expose the roots. The diameter and length of lateral root segments were measured with a ruler and caliper. Detailed excavation and root surface area measurement methods have been reported previously (Xu and Li, 2006). After investigation of root distribution the sampled trees were partitioned into below and above ground parts. The above ground parts were subdivided into foliage and woody parts. Specifically, a small fraction of roots with diameters $<2 \mathrm{~mm}$ were separated and measured for length and diameter with vernier caliper and ruler, which was used to calculate root length per dry mass (specific root length, SRL) and root surface area per dry mass (specific root area, SRA). All the parts were oven-dried at $65^{\circ} \mathrm{C}$ to a constant weight and the dry biomass was measured using an electric balance.

About $10 \mathrm{~g}$ of new, fully expanded leaves were collected from five individuals of each species during June 2010. Fresh leaf area was determined with a scanner in the laboratory. Leaves were oven-dried at $65^{\circ} \mathrm{C}$ to a constant weight and dry mass was measured. We calculated specific leaf area (SLA) basing on leaf area per unit of leaf dry mass. We calculated leaf surface areas of entire trees basing on dry biomass of foliage and SLA.

\subsection{Data analysis}

Descriptive statistics were used to calculate mean values and standard errors of the mean for each data set. Mean values of soil physical/chemical properties and morphological parameters for the two sites and species were compared with Student's t-tests. Charting was done with Origin 8.0 software (OriginLab Corp., Northampton, MA, USA).

\section{Results}

\subsection{Soil physical, chemical and hydraulic properties}

The soil particle sizes were $<2,000 \mu \mathrm{m}$. The soil on the interdune lowland consisted of $1.3 \%$ clay, $13.7 \%$ loam and $85 \%$ sand; the soil on the sand dune consisted of $0.3 \%$ clay, $3.8 \%$ loam and $96.2 \%$ sand. Figures $1 \mathrm{a}, \mathrm{b}$ and $\mathrm{c}$ show the soil physical properties at the two sites. Bulk density was significantly higher $(P<0.01)$ on the top of the dune $\left(1.6 \pm 0.02 \mathrm{~g} / \mathrm{cm}^{3}\right)$ than in the interdune $\left(1.4 \pm 0.01 \mathrm{~g} / \mathrm{cm}^{3}\right)$. The degree of porosity (ratio by volume) was $41.41 \pm 0.56$ on the dune and was significantly different at $38.49 \pm 0.63$ on the interdune $(P<0.01)$. The stable infiltration rate was $7.24 \pm 0.23 \mathrm{~mm} / \mathrm{min}$ on the dune and significantly different at $1.93 \pm 0.13 \mathrm{~mm} / \mathrm{min}$ on the interdune 
$(P<0.001)$. Soil $\mathrm{pH}$, electrical conductivity $(\mathrm{EC})$, soil organic carbon (SOC), soil total N (STN), soil total P (STP) and soil total K (STK) were higher on the interdune than on the dunes (Figs. 1d-i). Soil soluble ion concentrations of $\mathrm{K}^{+}, \mathrm{Na}^{+}, \mathrm{Ca}^{2+}, \mathrm{Mg}^{2+} \mathrm{Cl}^{-}, \mathrm{CO}_{3}{ }^{2-}$, $\mathrm{HCO}_{3}^{-}$and $\mathrm{SO}_{4}{ }^{2-}$ were also higher on the interdune than on the dunes (Fig. 2) which indicated the soil on the dune had less nutrients but was less saline than that of the interdune.

Figures 3 shows the average of soil moisture and corresponding soil water potential in each soil layer during the growing season and just after snow melt. On average, except in the upper soil layers $(0-40 \mathrm{~cm})$, soil moisture content in each layer on the dune was
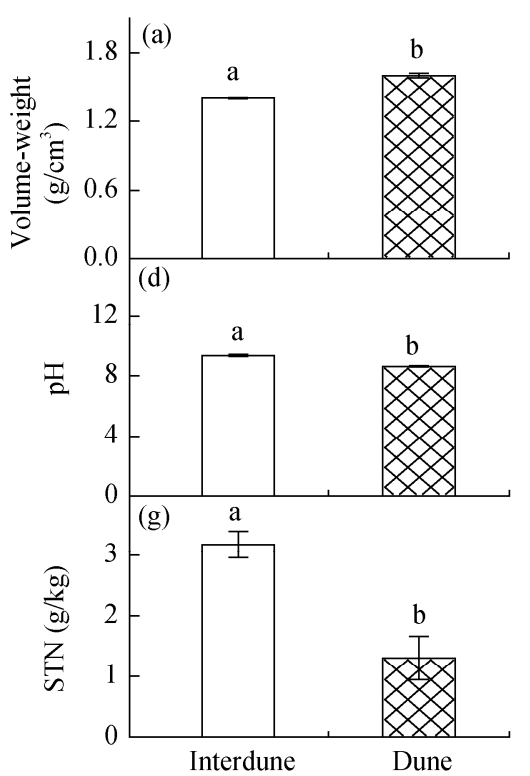
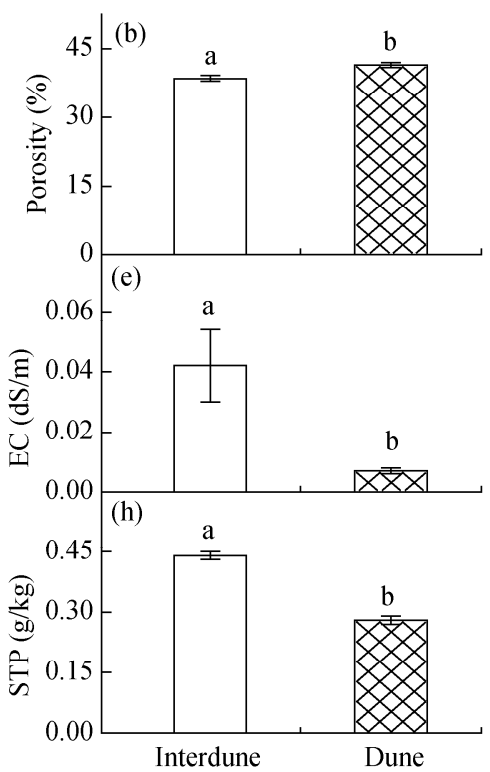

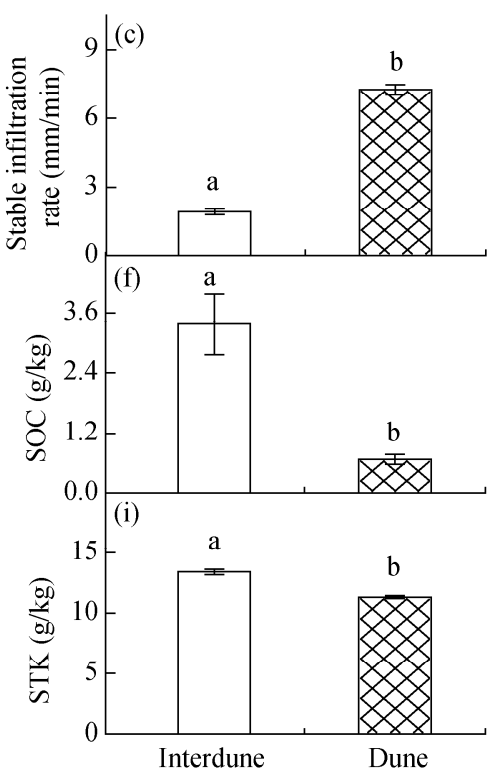

Fig. 1 Soil physical $(a-c)$ and chemical properties $(d-e)$ and nutrient contents $(f-i)$ at two sites, Values in the same panel labeled with different letters are significantly different at $P<0.05$. Mean \pm SE, $n=5$. EC, soil electrical conductivity; SOC, soil organic carbon; STN, soil total N; STP, soil total P; STK, soil total K.
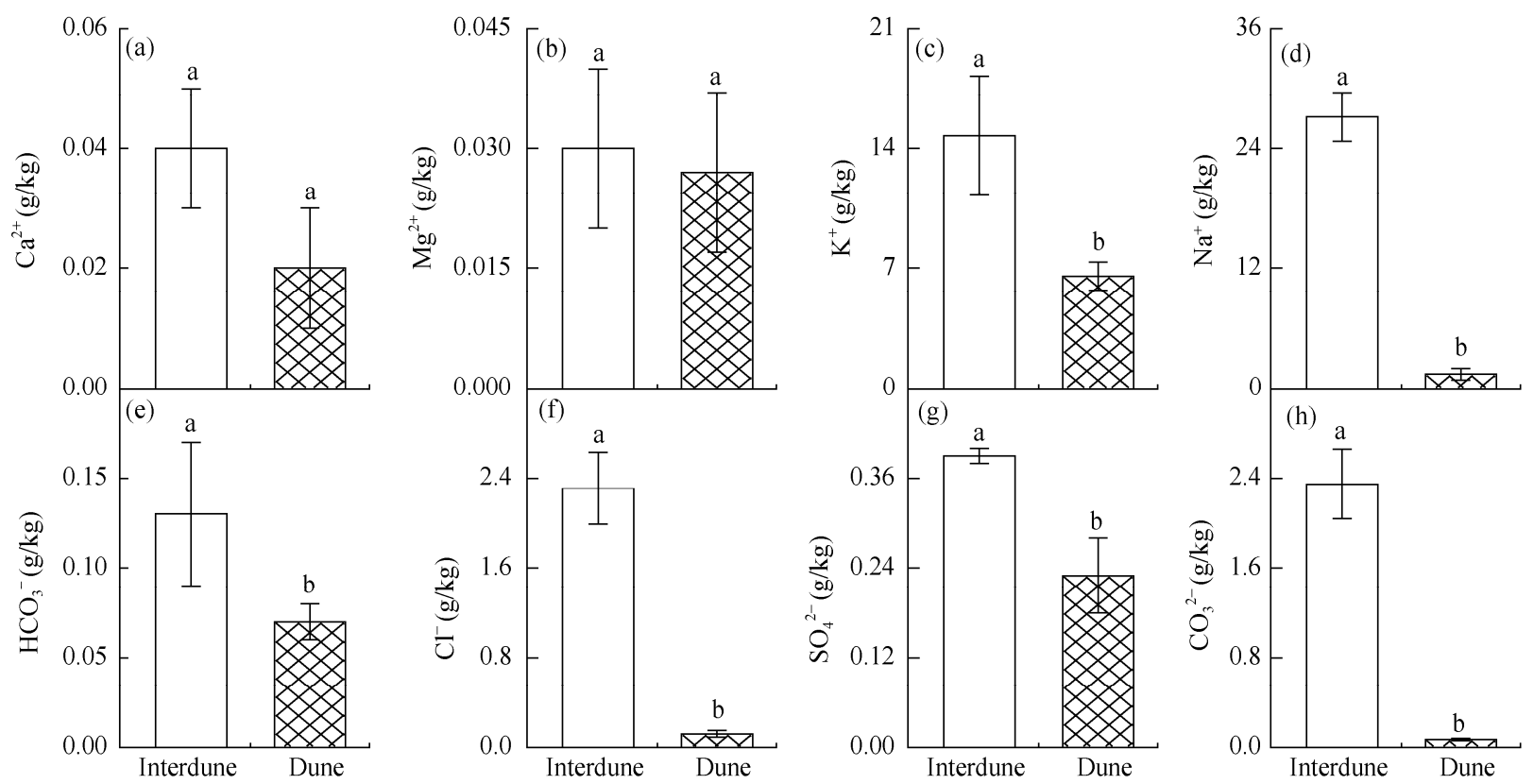

Fig. 2 Soil soluble ion content in two habitats. Values in the same panel labeled with different letters are significantly different at $P<0.05$. Mean \pm SE, $n=5$. 
lower than that of the interdune; the average soil water content within the soil profile during the entire growing season was $1.87 \%$ on the dune compared to $2.80 \%$ on the interdune $(P<0.001$; Fig. 3a). Figure $3 \mathrm{c}$ showssoil water content within the soil profile after snow melt. The maximum infiltration depth after snow melt was $1.6 \mathrm{~m}$ on the dune and $0.9 \mathrm{~m}$ on the interdune which was consistent with a stable infiltration rate in the two experiment plots (Fig. 1c). Figures $3 b$ and $d$ give the average of soil water potential in each soil layer during the growing season and after snow melt, respectively. On average, except in the upper soil layers $(0-40 \mathrm{~cm})$, soil water potential in each layer on the dune was non-significantly lower than that of the interdune; the average soil water potential within the soil profile of the entire growing season was -0.24 $\mathrm{MPa}$ on the dune compared to $-0.17 \mathrm{MPa}$ on the interdune $(P>0.05$; Fig. $3 \mathrm{~b})$. However, the difference was significant during summer drought. In late June 2010, at the beginning of the summer drought period, a soil water potential below $-1.5 \mathrm{MPa}$ occurred on the interdune from the soil surface to the soil depth of 0.4 $\mathrm{m}$. But this did not occur on the dune at the same period. In the extreme drought period (mid September) on the dunes, soil water potential was below $-1.5 \mathrm{MPa}$

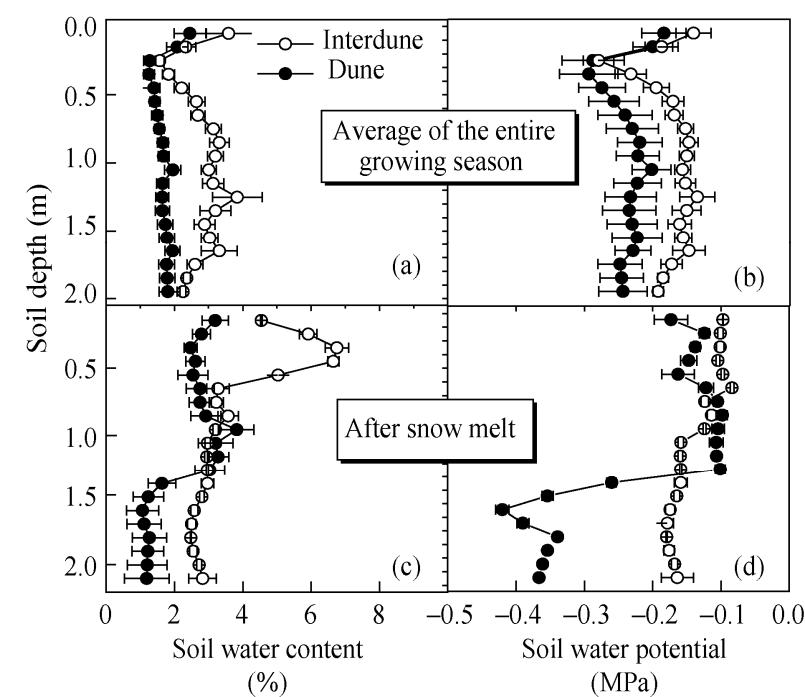

Fig. 3 Soil water content and soil water potential down the soil profile: (a) average soil water content during the peak growing season from June to September 2010; mean \pm SE; (b) corresponding average soil water potential at each depth; mean \pm SE; (c) soil water content at each depth immediately after snow melt; (d) corresponding soil water potential at each depth after snow melt. from the soil surface to the depth of $1.6 \mathrm{~m}$, but on the interdune, the same occurred from the soil surface to the depth of only $0.5 \mathrm{~m}$.

\subsection{Seedling emergence and survival}

Seedlings began to emerge 45 days after being planted on 23 March 2010. Most seedlings emerged from middle to late April. At the same habitat emergence was significantly higher for the native species than the foreign species. For the same species there was also significantly higher emergence on its native habitat than on the adjacent one. High seedlings mortality appeared at the beginning of May and lasted to early June. For the same species there were more seedling deaths on the exchange habitat than their native habitat. In the same habitat, there was more seedling survival for the native species than the foreign species. Compared with their native habitats, very few individuals had survived on the exchange habitat at the end of the growing season (Fig. 4).

\subsection{Biomass allocation and morphological traits}

The 1-year-old seedlings of $H$. ammodendron had higher total biomass, root dry mass, shoot dry mass but a lower root:shoot dry mass ratio and root:leaf surface area ratio than $H$. persicum (Fig. 5). Compared to $H$. ammodendron, $H$. persicum invested more photosynthate to belowground resources as the root:shoot biomass ratio indicated. Root depth was shallower for $H$. ammodendron than that of $H$. persicum for the 1-year old seedlings (Fig. 5). The distribution of surface area of lateral root was shown in Fig. 6. The lateral root surface area of $H$. ammodendron was higher than that of $H$. persicum. The results of investigation of morphological traits showed H. ammodendron had higher specific leaf area and smaller specific root length and specific root area than that of $H$. persicum (Fig. 7).

\section{Discussion and conclusion}

The most ecologically relevant biological aspects investigated were seedling recruitment, phenotypic trait performances (morphological traits) and biomass allocation. We emphasize the importance of the impact of soil factors on seedling recruitment in determining the current typical habitat distribution. Selection favored the more water stress tolerant and nutrient shortage 


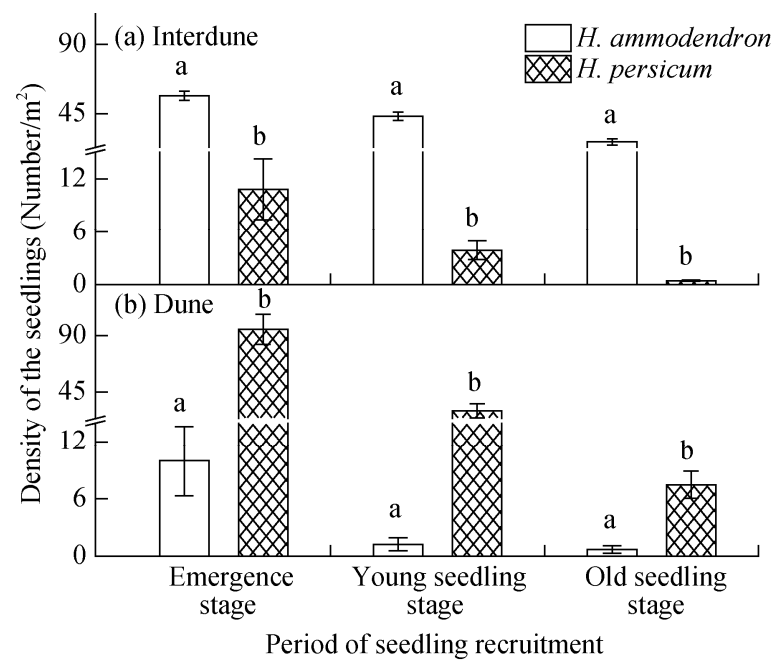

Fig. 4 Change of the density of $H$. ammodendron and $H$. persicum seedlings in interdune lowlands (a) and sand dunes (b) in their natural habitats and foreign habitats under field conditions in 2010. The emergence stage was from 15 to 30 April; the number of the seedlings of each species in 10 plots $\left(1-\mathrm{m}^{2}\right.$ for each plot) was counted five times at 3 day intervals and then averaged, so the value was the mean $\pm S E$ with 50 replicates during germination. The young seedling stage was from 1 May to 15 June, the observations were conducted eight times with a 6-7 day intervals and the value was the mean \pm SE with 80 replicates. The older seedling stage was from 15 June to 14 September, counting was conducted 15 times with 6-7 day intervals and the value was mean $\pm S E$ with 150 replicates. Values in the same panel labeled with different letters are significantly different at $P<0.05$.
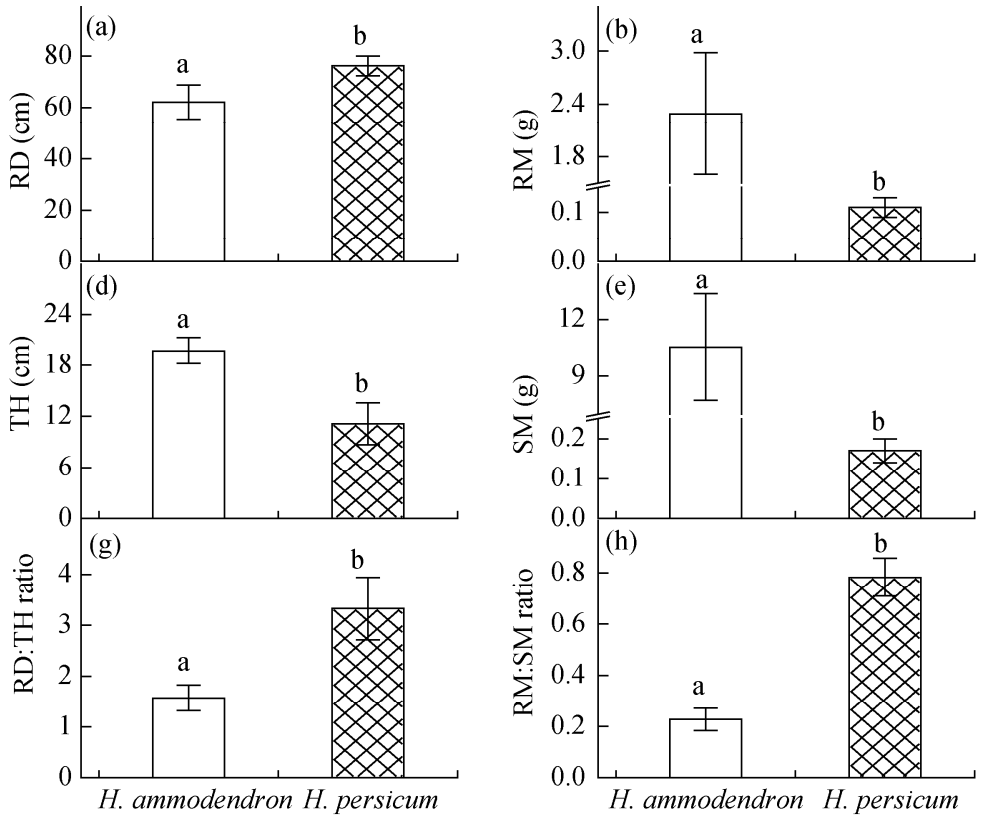

Fig. 5 One-year-old seedling rooting depth:tree height ratio ( $a, d, e)$, biomass allocation pattern $(b, e, h)$ and root to leaf area ratio (c, f, i). Different letters in the same panel indicate significant differences at $P<0.05$. Mean $\pm \mathrm{SE}, n=5$. RD, rooting depth; $\mathrm{TH}$, tree height; RM, root dry biomass; SM, shoot dry biomass; RA, lateral root surface area; LA, leaf surface area.

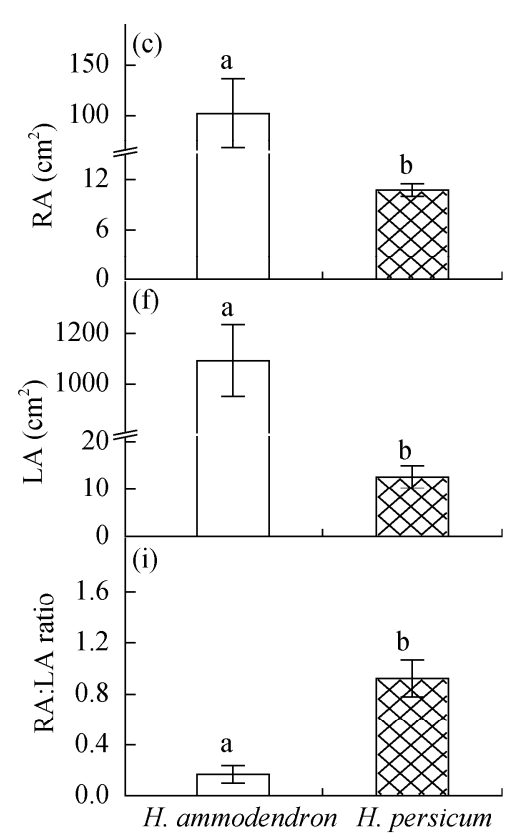

adapted H. persicum's occupation of the top dunes and the more salinity adapted $H$. ammodendron's occupation of the lowland between the dunes.

\subsection{Determinants of dune-interdune species dis- tribution}

We used reciprocal transplants to evaluate the influence of soil factors on seedling recruitment and the importance of those factors to the dune-interdune species distribution. The two species studied here had much lower seedling densities when planted on soil substrates where they did not normally occupy than when planted on their normal soil substrates during the recruitment stage (Fig. 4). Seedling performance and survival of species was better on its own soil type rather than on the exchange soil type. These results indicate soil factors affected seedling emergence and establishment. Because of the higher soil salinity between the sand dunes (Figs. 1 and 2) and lower seed germination and seedling survival on the higher $\mathrm{NaCl}$ concentrations in the laboratory (Song et al., 2005, 2006), we can conclude soil salinity constrains $H$. persicum distribution on the lowland between the dunes. 


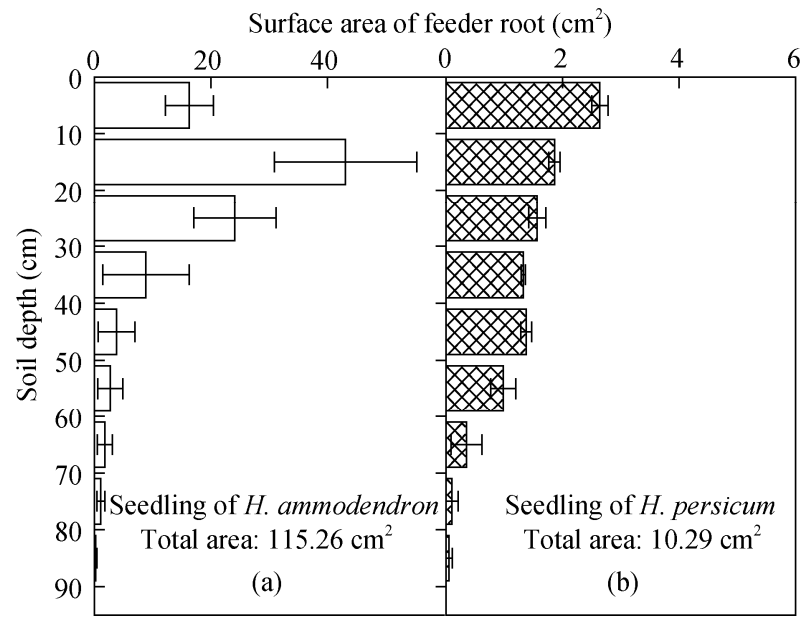

Fig. 6 Distribution of the surface area of the lateral roots in the soil profile at $10-\mathrm{cm}$ depth intervals. One-year-old seedlings of $H$. ammodendron and $H$. persicum were excavated in the experimental plots on interdune lowlands (a) and the top of sand dunes (b). Mean \pm SE, $n=5$.

Padilla and Pugnaire (2007) reported maximum root depth is important for species survival during periods of drought. Drought in desert ecosystems was also closely related to plant distribution (Barnes and Harrison, 1982; Groom, 2004). For H. ammodendron, low soil salinity $\mathrm{n}$ the dune may partially constrain seedling survival as reported by Tobe (2000): a hydroponic culture of $H$. ammodendron over around 3 months with $\mathrm{NaCl}$ solutions of $0,200,400$ and $600 \mathrm{mmol} / \mathrm{kg}$ showed that the survival was highest $(82.3 \%)$ at $400 \mathrm{mmol} / \mathrm{kg} \mathrm{NaCl}$. Also, the slower root vertical extension speed of $H$. ammodendron compared to that of $H$. persicum in the seedling stage (Fig. 7a) may lead to the higher seedling mortality on the dunes. The higher mortality of $H$. ammodendron on the dunes may be aggravated by lower water availability in the dunes than occurs in their natural interdune habitat (Fig. 3). Habitat heterogeneity in soil water and salinity resulted in strong selection pressures on germinating seedlings. The differing adaptability of these two species to salinity and soil water conditions during the recruitment stage eventually determines adult distribution patterns. Therefore, the contrasting germination and survival requirements between the two species in their recruitment stage lead to preferential germination and seedling emergence on its native soil substrate. Our findings support the hypothesis that differences in regeneration in a dune/interdune system determine the typical dune/interdune distribution of the adult trees.

\subsection{Advantages of the two Haloxylon species in their own environments}

The trade-off in allocation patterns and phenotypic traits is important for maintaining a plant's adaptation to environmental limiting factors (Kitajima, 1994; Cornelissen et al., 1996) and is closely related to species distribution (Poot and Lambers, 2003, 2008). H. Persicum with a smaller stature (smaller total biomass) invested a larger allocation of biomass to roots, maintained a larger root/shoot ratio (Figs. 5 b-i) and larger specific root length (Fig. 7a) and specific root area (Fig. 7b). All of these make H. persicum more adapted than $H$. ammodendron to water stress and nutrient shortage in a water- and nutrient-limited environment. These results were consistent with our second work hypothesis. A comparison between rare and common
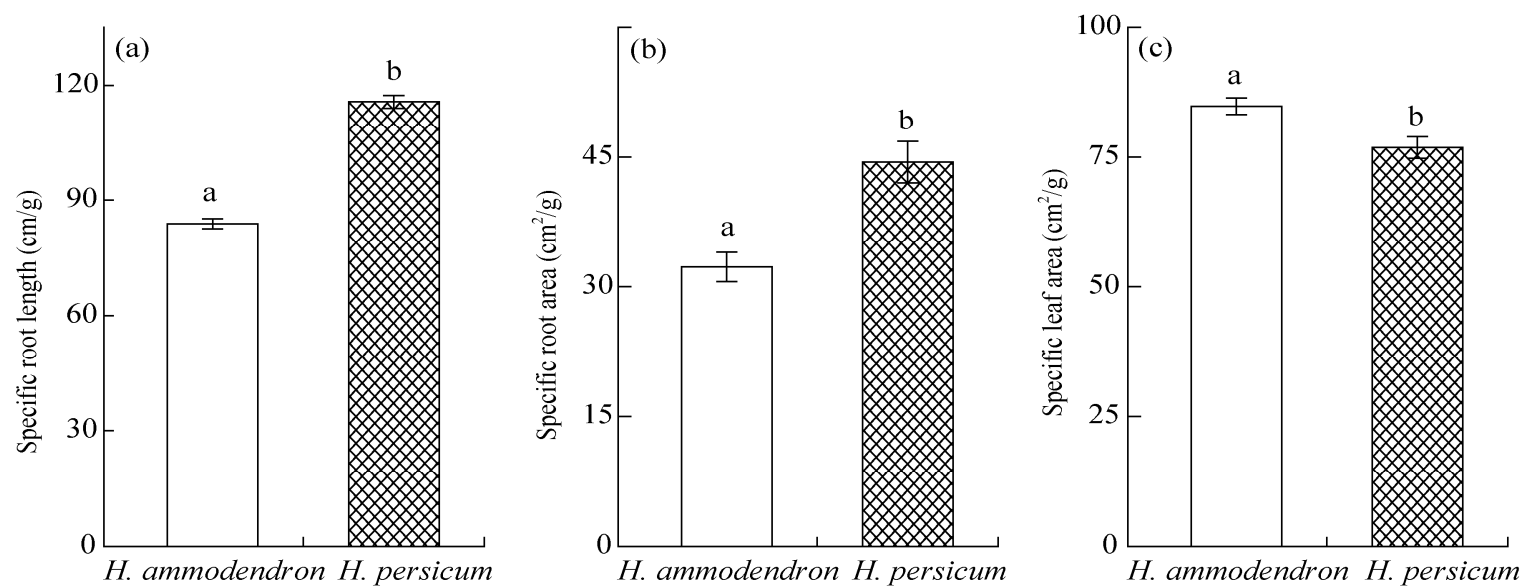

Fig. 7 Lateral root and leaf morphological characteristics of the two Haloxylon species: (a) specific root length; (b) specific root area and (c) specific leaf area. Different letters in the same panel indicate significant differences at $P<0.05$. Mean $\pm \mathrm{SE}, n=3$. 
species by Poot and Lambers (2003) showed the rade-off in whole plant biomass allocation (investment in root or shoot) and within root biomass allocation (high or low specific root length) may cause them to be well adapted to their own environment, but poorly adapted to others. However, root:shoot ratio is obviously not static, but changes with plant size, and may have to be followed over a longer period for differences to be observed. Additionally, total root length is a better predictor of explorable soil volume and, therefore, of the capacity of roots to absorb nutrients and water than absolute root mass. Furthermore, competition between congeneric species in the boundary zone is frequently more intense than between unrelated species (Walck et al., 2001; Milla et al., 2011) and responsible for the large differences in these two species' geographical distributions and habitats (Theodose and Bowman, 1997; McGill, 2010). Therefore, the role of the competition in the two species' spatial distribution pattern should receive more attention.

The results from our study indicated the two species adapt to salinity and soil water conditions differently during the germination and seedling establishment stages and this strongly determined the distribution patterns of the two species. Both species had higher densities of seedlings at every stage of recruitment in their native habitat than the adjacent habitat. H. persicum on the dunes had lower total dry biomass, shoot and root dry biomass, but allocated a higher percentage of its biomass to roots and possessed a higher specific root length and specific root area by phenotypic traits specialization than that of $H$. ammodendron on the interdune. The differences in morphology and allocation facilitated the ability of these two species to persist in their own environments. Selection favored the higher drought tolerant and barren adapted $H$. persicum's occupation of the dunes and the higher salinity adapted $H$. ammodendron's occupation of the lowland between the dunes.

\section{Acknowledgements}

The study was supported by the Western Light Program of the Chinese Academy of Sciences (XBBS201001), the National Natural Science Foundation of China (40971042, 41371079) and the International Science \& Technology Cooperation Program of China (2010DFA92720). We thank the staff of the Fukang National Field Scientific Observation and Research Station for Desert Ecosystems for their excellent field and laboratory assistance.

\section{References}

Agrawal A A. 2001. Phenotypic plasticity in the interactions and evolution of species. Science, 294: 321-326.

Araújo M B, Luoto M. 2007. The importance of biotic interactions for modelling species distributions under climate change. Global Ecology and Biogeography, 16: 743-753.

Barnes P W, Harrison A T. 1982. Species distribution and community organization in a Nebraska Sandhills mixed prairie as influenced by plant/soil-water relationships. Oecologia, 52: 192-201.

Baskauf C J, Eickmeier W G. 1994. Comparative ecophysiology of a rare and a widespread species of Echinacea (Asteraceae). American Journal of Botany, 81: 958-964.

Casazza G, Zappa E, Mariotti M G, et al. 2008. Ecological and historical factors affecting distribution pattern and richness of endemic plant species: the case of the Maritime and Ligurian Alps hotspot. Diversity and Distributions, 14: 47-58.

Cohen Y, Fuchs M, Cohen S. 1983. Resistance to water uptake in a mature Citrus tree. Journal of Experimental Botany, 34: 451-460.

Cornelissen J H C, Diez P C, Hunt R. 1996. Seedling growth, allocation and leaf attributes in a wide range of woody plant species and types. Journal of Experimental Botany, 84: 755-765.

Davis M B, Shaw R G. 2001. Range shifts and adaptive responses to quaternary climate change. Science, 292: 673-679.

Davis S D. 1991. Lack of niche differentiation in adult shrubs implicates the importance of the regeneration niche. Trends in Ecology \& Evolution, 6: 272-274.

Daws M I, Burslem D F R P, Crabtree L M, et al. 2002. Differences in seed germination responses may promote coexistence of four sympatric Piper species. Functional Ecology, 16: 258-267.

Eiserhardt W L, Svenning J C, Kissling W D, et al. 2011. Geographical ecology of the palms (Arecaceae): determinants of diversity and distributions across spatial scales. Annals of Botany, 108: 1391-1416

Ellers J, Stuefer J. 2010. Frontiers in phenotypic plasticity research: new questions about mechanisms, induced responses and ecological impacts. Evolutionary Ecology, 24: 523-526.

Engelbrecht B M J, Comita L S, Condit R, et al. 2007. Drought sensitivity shapes species distribution patterns in tropical forests. Nature, 447: 80-82.

Gaston K J. 2009. Geographic range limits: achieving synthesis. Proceedings of the Royal Society B: Biological Sciences, 276: 1395-1406.

Ghalambor C K, McKay J K, Carroll S P, et al. 2007. Adaptive versus non-adaptive phenotypic plasticity and the potential for contemporary adaptation in new environments. Functional Ecology, 21: 394-340.

Gianoli E, Valladares F. 2012. Studying phenotypic plasticity: the advantages of a broad approach. Biological Journal of the Linnean Society, 105: 1-7. 
Griffith T, Sultan S E. 2012. Field-based insights to the evolution of specialization: plasticity and fitness across habitats in a specialist/generalist species pair. Ecology and Evolution, 2: 778-791.

Grigg A M, Veneklaas E J, Lambers H. 2008. Water relations and mineral nutrition of closely related woody plant species on desert dunes and interdunes. Australian Journal of Botany, 56: 27-43.

Groom P K. 2004. Rooting depth and plant water relations explain species distribution patterns within a sandplain landscape. Functional Plant Biology, 31: 423-428.

Honnay O, Verheyen K, Butaye J, et al. 2002. Possible effects of habitat fragmentation and climate change on the range of forest plant species. Ecology Letters, 5: 525-530.

Hu Y H, Sha L Q, Blanchet F G, et al. 2012. Dominant species and dispersal limitation regulate tree species distributions in a 20-ha plot in Xishuangbanna, southwest China. Oikos, 121: 952-960.

John R, Dalling J W, Harms K E, et al. 2007. Soil nutrients influence spatial distributions of tropical tree species. Proceedings of the National Academy of Sciences, USA, 104: 864-869.

Kitajima K. 1994. Relative importance of photosynthetic traits and allocation patterns as correlates of seedling shade tolerance of 13 tropical trees. Oecologia, 98: 419-428.

Levin S A. 1992. The problem of pattern and scale in ecology: the Robert H. MacArthur award lecture. Ecology, 73: 1943-1967.

Li C, Li Y, Ma J. 2011. Spatial heterogeneity of soil chemical properties at fine scales induced by Haloxylon ammodendron (Chenopodiaceae) plants in a sandy desert. Ecological Research, 26: 385-394.

Markesteijn L, Iraipi J, Bongers F, et al. 2010. Seasonal variation in soil and plant water potentials in a Bolivian tropical moist and dry forest. Journal of Tropical Ecology, 26: 497-508.

Masaki T, Osumi K, Takahashi K, et al. 2007. Effects of microenvironmental heterogeneity on the seed-to-seedling process and tree coexistence in a riparian forest. Ecological Research, 22: 724-734.

Matesanz S, Gianoli E, Valladares F. 2010. Global change and the evolution of phenotypic plasticity in plants. Annals of the New York Academy of Sciences, 1206: 35-55.

Maun M A, Perumal J. 1999. Zonation of vegetation on lacustrine coastal dunes: effects of burial by sand. Ecology Letters, 2: 14-18.

McDowall R M. 2004. What biogeography is: a place for process. Journal of Biogeography, 31: 345-351.

McGill B J. 2010. Matters of scale. Science, 328: 575-576.

Milla R, Escudero A, Iriondo J M. 2011. Congruence between geographic range distribution and local competitive ability of two $\mathrm{Lu}$ pinus species. American Journal of Botany, 98: 1456-1464.

Moreno-Casasola P. 1988. Patterns of plant species distribution on coastal dunes along the Gulf of Mexico. Journal of Biogeography, 15: 787-806

Murray B R, Thrall P H, Gill A M, et al. 2002. How plant life-history and ecological traits relate to species rarity and commonness at varying spatial scales. Austral Ecology, 27: 291-310.

Mustart P J, Cowling R M. 1993. The role of regeneration stages in the distribution of edaphically restricted Fynbos proteaceae. Ecology, 74: 1490-1499.

Nelson D W, Sommers L E. 1982. Total carbon, organic carbon, and organic matter. In: Page A L, Miller R H, Keeney D R. Methods of
Soil Analysis ( $2^{\text {nd }}$ ed). Madison: America Society of Agronomy, 535-579.

Nicotra A B, Atkin O K, Bonser S P, et al. 2010. Plant phenotypic plasticity in a changing climate. Trends in Plant Science, 15: 684-692.

Olff H, Huisman J, Tooren B F V. 1993. Species dynamics and nutrient accumulation during early primary succession in coastal sand dunes. Journal of Ecology, 81: 693-706.

Padilla F M, Pugnaire F I. 2007. Rooting depth and soil moisture control Mediterranean woody seedling survival during drought. Functional Ecology, 21: 489-495. doi: 10.1111/j.1365-2435.2007.01267.x.

Palm C, Sanchez P, Ahamed S, et al. 2007. Soils: a contemporary perspective. Annual Review of Environment and Resources, 32: 99-129.

Patnaik P. 1997. Handbook of Environmental Analysis. Boca Raton: Lewis Publisher.

Pineda-GarcíA F, Paz H, Tinoco-Ojanguren C. 2011. Morphological and physiological differentiation of seedlings between dry and wet habitats in a tropical dry forest. Plant Cell and Environment, 34: $1536-1547$.

Pemadasa M A, Greig-Smith P, Lovell P H. 1974. A quantitative description of the distribution of annuals in the dune system at Aberffraw, Anglesey. Journal of Ecology, 62: 379-402.

Pennisi E. 2005. What determines species diversity? Science, 309: 90. doi: 10.1126/science.309.5731.90.

Phillips A M, Kennedy D J, Cross M. 2001. Biology, distribution, and abundance of Peirson's milkvetch and other special status plants of the Algodones Dunes, California. American Sand Association, 29.

Pichancourt J B, van Klinken R D. 2012. Phenotypic plasticity influences the size, shape and dynamics of the geographic distribution of an invasive plant. Plos One, 7: e32323.

Poot P, Lambers H. 2003. Are trade-offs in allocation pattern and root morphology related to species abundance? A congeneric comparison between rare and common species in the South-Western Australian Flora. Journal of Ecology, 91: 58-67.

Poot P, Lambers H. 2008. Shallow-soil endemics: adaptive advantages and constraints of a specialized root-system morphology. New Phytologist, 178: 371-381.

Pratt R B, Jacobsen A L, Mohla R, et al. 2008. Linkage between water stress tolerance and life history type in seedlings of nine chaparral species (Rhamnaceae). Journal of Ecology, 96: 1252-1265.

Richards M B, Stock W D, Cowling R M. 1995. Water relations of seedlings and adults of two Fynbos protea species in relation to their distribution patterns. Functional Ecology, 9: 575-583.

Richards M B, Cowling R M, Stock W D. 1997. Soil factors and competition as determinants of the distribution of six Fynbos proteaceae species. Oikos, 79: 394-406.

Rietkerk M, Ouedraogo T, Kumar L, et al. 2002. Fine-scale spatial distribution of plants and resources on a sandy soil in the Sahel. Plant and Soil, 239: 69-77.

Robertson G P, Crum J R, Ellis B G. 1993. The spatial variability of soil resources following long-term disturbance. Oecologia, 96: 451-456.

Sage R F. 1994. Acclimation of photosynthesis to increasing atmospheric $\mathrm{CO}_{2}$ : the gas exchange perspective. Photosynthesis Research, 39: 351-368.

Schei F H, Blom H H, Gjerde I, et al. 2012. Fine-scale distribution and abundance of epiphytic lichens: environmental filtering or local 
dispersal dynamics? Journal of Vegetation Science, 23: 459-470.

Sexton J P, McIntyre P J, Angert A L, et al. 2009. Evolution and ecology of species range limits. Annual Review of Ecology, Evolution, and Systematics, 40: 415-436.

Song J, Feng G, Tian C Y, et al. 2005. Strategies for adaptation of Suaeda physophora, Haloxylon ammodendron and Haloxylon persicum to a saline environment during seed-germination stage. Annals of Botany, 96: 399-405.

Song J, Feng G, Tian C Y, et al. 2006. Osmotic adjustment traits of Suaeda physophora, Haloxylon ammodendron and Haloxylon persicum in field or controlled conditions. Plant Science, 170: 113-119.

Su P, Cheng G, Yan Q, Liu X. 2007. Photosynthetic regulation of $\mathrm{C}_{4}$ desert plant Haloxylon ammodendron under drought stress. Plant Growth Regulation, 51: 139-147.

Sultan S E. 2001. Phenotypic plasticity for fitness components in Polygonum species of contrasting ecological breadth. Ecology, 82: 328-343

Sultan S E. 2003. Phenotypic plasticity in plants: a case study in ecological development. Evolution \& Development, 5: 25-33.

Svenning J C, Skov F. 2007. Ice age legacies in the geographical distribution of tree species richness in Europe. Global Ecology and Biogeography, 16: 234-245.

Svenning J C, Normand S, Skov F. 2008. Postglacial dispersal limitation of widespread forest plant species in nemoral Europe. Ecography, 31: 316-326.

Svenning J C, Harlev D, Sørensen M, et al. 2009. Topographic and spatial controls of palm species distributions in a montane rain forest, southern Ecuador. Biodiversity and Conservation, 18: 219-228.

Theodose T A, Bowman W D. 1997. The influence of interspecific competition on the distribution of an alpine graminoid: evidence for the importance of plant competition in an extreme environment. Oikos, 79: 101-114.

Tobe Kazuo, Li X, Omasa K. 2000. Effects of sodium chloride on seed germination and growth of two Chinese desert shrubs, Haloxylon ammodendron and $H$. persicum (Chenopodiaceae). Australian Journal of Botany, 48: 455-460.
Tuomisto H, Poulsen A D. 1996. Influence of edaphic specialization on pteridophyte distribution in neotropical rain forests. Journal of Biogeography, 23: 283-293.

Van Genuchten M T. 1980. A closed-form equation for predicting the hydraulic conductivity of unsaturated soils. Soil Science Society of America Journal, 44(5): 892-898.

Walck J L, Baskin J M, Baskin C C. 2001. Why is Solidago shortii narrowly endemic and S. altissima geographically widespread? A comprehensive comparative study of biological traits. Journal of Biogeography, 28: 1221-1237.

Walther G R, Gritti E S, Berger S, et al. 2007. Palms tracking climate change. Global Ecology and Biogeography, 16: 801-809.

Wang H, McArthur E D, Sanderson S C, et al. 1997. Narrow hybrid zone between two subspecies of big sagebrush (Artemisia tridentata: Asteraceae). IV. reciprocal transplant experiments. Evolution, 51: 95-102.

West A G, Hultine K R, Jackson T L, et al. 2007. Differential summer water use by Pinus edulis and Juniperus osteosperma reflects contrasting hydraulic characteristics Tree Physiology, 27 (12): 1711-1720.

Xu G Q. Li Y. 2008. Rooting depth and leaf hydraulic conductance in the xeric tree Haloxyolon ammodendron growing at sites of contrasting soil texture. Functional Plant Biology, 35: 1234-1242.

$\mathrm{Xu} \mathrm{H,} \mathrm{Li} \mathrm{Y.} \mathrm{2006.} \mathrm{Water-use} \mathrm{strategy} \mathrm{of} \mathrm{three} \mathrm{central} \mathrm{Asian} \mathrm{desert}$ shrubs and their responses to rain pulse events. Plant and Soil, 285: 5-17.

$\mathrm{Xu}$ L, Liu H, Chu X, Su K. 2006. Desert vegetation patterns at the northern foot of Tianshan Mountains: The role of soil conditions. Flora, 201: 44-50.

Zimmermann N E, Yoccoz N G, Edwards T C, et al. 2009. Climatic extremes improve predictions of spatial patterns of tree species. Proceedings of the National Academy of Sciences, USA, 106: 19723-19728.

Zuo X, Zhao X, Zhao H, et al. 2009. Spatial heterogeneity of soil properties and vegetation-soil relationships following vegetation restoration of mobile dunes in Horqin Sandy Land, Northern China. Plant and Soil, 318: 153-167. 